\title{
Improving Strategies for Information-Based Educational and Teaching Abilities of Newly Appointed College Teachers Using the TPACK Hierarchical Model
}

\author{
https://doi.org/10.3991/ijet.v15i14.15307 \\ Hanhui Lin \\ South China Normal University, Guangzhou, China \\ Guangdong University of Finance and Economics, Guangzhou, China \\ Muxiong Huang $(\bowtie)$ \\ South China Normal University, Guangzhou, China \\ Guangdong University of Education, Guangzhou, China \\ 65721450 eqq. com
}

\begin{abstract}
The improvement of strategies for information-based educational and teaching abilities of newly appointed teachers should be substantially investigated urgently based on the policy level of various countries or the reality of colleges and universities. However, from the perspective of the Technological Pedagogical Content Knowledge (TPACK) hierarchy, there are only a few studies on the strategies to improve the information-based educational and teaching abilities of newly appointed teachers. Therefore, this study analyzed the relationships between the three cores and four composite elements, designed the ability improvement strategy corresponding to each element, designed a hierarchical improving strategy which corresponds to 20 training contents, and used quasi-experimental research methods to apply the strategy to the 2019 newly recruited teacher training system of Guangdong University of Finance and Economics. Through the implementation of the training strategy for one semester and effect evaluation, combined with the comparative analysis of the training evaluation data of newly appointed teachers who did not implement this strategy in 2018, it shows that the implementation of the strategy can significantly improve the information-based educational and teaching ability of newly appointed teachers, with good results.
\end{abstract}

Keywords-TPACK, newly appointed teachers, informationization, educational and teaching ability.

\section{Introduction}

The rapid development of information technology in recent years has prompted various countries to attach immense importance to the cultivation of teachers' information-based educational and teaching abilities in the new era, and promulgate the related documents to guide and support training of newly appointed teachers. In 
2016, the US Department of Education published the fifth national educational technology program titled Future Ready Learning: Reimagining the Role of Technology in Education. This program particularly highlights the redesign of the teaching training plan and provides technical support and multi-aspect linkage for educational work to realize effective teaching. The UK released the 2015-2020 Strategic Plan of Ministry of Education: World-Class Education and Health Care and formulated the future five-year educational development strategy and program. This program proposes the energetic elevation of the establishment rate of the science, technology, engineering, and mathematics curriculum; and improvement of the quality of the related curriculum and teachers' technological level. In 2016, China released The Notice of General Office Ministry of Education About Launching Implementation of National Training Demonstration Program for Newly Appointed College Teachers. This document clearly points out that training contents include teaching design, teaching activity, teaching evaluation, teaching reflection and research, latest information-based teaching technology, teaching model under information environment, and application of online teaching resources and learning tools. Evidently, the policy orientations of various countries show that they have attached importance to faculty training to improve the skills and level of educational and teaching work, teachers' abilities to utilize modern educational technology and application level, teaching quality, and educational and teaching reform.

Newly appointed college teachers belong to a young generation who are good at accepting new ideas, are fresh troops and reserves of colleges and universities, and an emerging force in promoting teaching reform with the most teaching creativity [1] [2].Moreover, newly appointed teacher training is a critical link in the role transformation of teachers, and will influence whether these teachers can adapt to their roles, master advanced information-based educational concepts and basic information-based educational and teaching skills, effectively impart knowledge to students by providing information and using all types of teaching means and methods, and improve educational and teaching abilities under an information environment [3]. Therefore, a set of improving strategies for information-based educational and teaching abilities of newly appointed college teachers should be explored.

\section{State of Art}

The technological pedagogical content knowledge (TPACK) model becomes a teacher educational technology ability research tool widely used by local and international teacher training researchers [4]. The related studies use the research on information-based educational and teaching abilities as basis and are mainly concentrated on two aspects. The first aspect uses some components of the TPACK seven knowledge system to design training strategy research, while the other aspect involves the research on designing evaluation scale with TPACK as the evaluation system. As some examples for the former, $\mathrm{Xu}$ Xuemin conducted research on the cultivation of information-based educational and teaching abilities based on the TPACK model, and constructed a training model combining pre- and in-service 
training, centralized and decentralized learning, technical knowledge and practical application, and autonomous learning and collaborative communication [5]; Liu Lei et al. studied the cultivation of pre-service teachers' information-based teaching ability from the perspective of TPACK theory, and constructed a training model in three stages: information-based teaching resource acquisition and production, work design and production, and effect evaluation [6]; Manoli Pifarre et al. conducted a research titled "A Technology-enhanced Pedagogical Framework to Promote Collaborative Creativity in Secondary Education," and constructed a training model from the perspective of collaborative learning and communication on creative learning [7]. As some examples for the latter, Hu Lun et al. performed "A Study on the Revision of College Teachers' TPACK Ability Scale," and revised and processed foreign TPACK knowledge and hierarchical measurement scale. The reliability and validity of the scale were re-tested on the basis of localization, and the validity and availability of the scale were finally determined [8]; Teemu Valtone et al. conducted the research titled "Examining Pre-service Teachers' Technological Pedagogical Content Knowledge as Evolving Knowledge Domains: A Longitudinal Approach," which focused on outlining the development and changes in pre-service teachers' TPACK assessments during the first three years in teacher education [9]; Didem Akyuz conducted the study "Measuring Technological Pedagogical Content Knowledge (TPACK) Through Performance Assessment," which clarified the relationships between the components of the framework and how to perform TPACK assessment remain, and analyzed lesson plans collected from 138 pre-service mathematics teachers from a technologyintegration course over 5 years [10].

The existing research on teacher training with TPACK as the model has focused on the improvement of only part of the abilities of newly appointed college teachers, but failed to design the training contents according to the seven parts and unable to consider the logical relationship among the seven parts. TPACK is based on technological knowledge (TK), pedagogical knowledge (PK), and content knowledge (CK), and the four other parts are based on the three. Studies have been conducted on TPACK as an evaluation system and employed it in the evaluation of the teaching effects without taking advantage of the TPACK system in the design of teacher training strategies. The object of the existing research also focuses on the pre-service study of primary and secondary school teachers, specifically the study on students' time of primary and secondary school teachers. By contrast, the research on the onesemester training system of newly appointed college teachers is minimal. Using TPACK for training strategy design, and the research of the implementation effect verification throughout a semester is few. Therefore, improving strategies for information-based educational and teaching abilities of newly appointed teachers should be extensively investigated for either national policy guidance or research status. 


\section{$3 \quad$ Strategy and Experimental Design}

\subsection{Introduction of TPACK}

This framework was initially abbreviated by the acronym TPCK [11] but was later renamed as TPACK to better reflect the inter-dependence of the contributing knowledge domains. These knowledge domains are TK, PK, and CK. Various blended knowledge domains can be derived from their intersections, such as pedagogical content knowledge (TPK), technological pedagogical knowledge (TCK), technological content knowledge (PCK), and TPACK [12] (see Fig. 1).

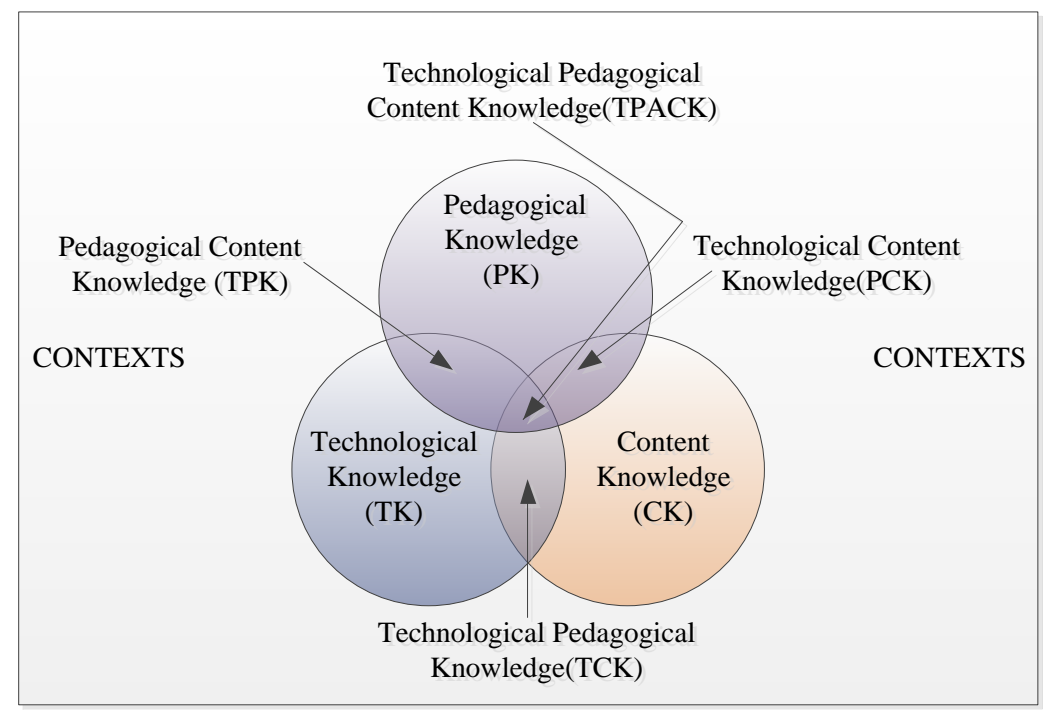

Fig. 1. TPACK model

TK is knowledge of the method of using different information and communications technology (ICT) tools and applications. PK is knowledge of different teaching and learning approaches, learning theories, and assessment methods without references to any specific content areas. CK is knowledge of subject matter and different disciplines without consideration of teaching the subject matter. PCK is knowledge of the method of combining CK and PK to make the learning of the subject matter easy and the content understandable. TPK is knowledge of how to maximize the appropriate ICT to support certain teaching and learning approaches without considering subject matter. TCK is knowledge of the manner of representing, conducting research, and creating ICT content without considering teaching. ICT knowledge is used by content experts. TPACK is knowledge of combining different areas and using the appropriate pedagogical approaches for certain content with appropriate ICT [13]. 


\subsection{Strategy design}

The TPACK model was comprehensively analyzed, combining the characteristics of newly appointed teachers: extensive professional knowledge and possessing of certain technical knowledge but lacking in teaching knowledge. The three knowledge types (i.e., TK, PK, CK) constitute the basis for other mixed knowledge (i.e., TPK, TCK, PCK, TPACK) and the key deciding other mixed-type knowledge. Thus, TK, $\mathrm{PK}$, and $\mathrm{CK}$ are placed at the lowest layer in the strategy design (i.e., first layer). The second layer includes TCK and PCK because subject content is the basis for teaching knowledge and technical knowledge, and newly appointed teachers have good subject foundation. TPK is placed at the third layer. The most comprehensive TPACK is placed at the highest layer (i.e., fourth layer). The training strategy is designed in a hierarchical manner according to the characteristics of newly appointed teachers and the TPACK model. The ability improving strategy is shown in Fig. 2.

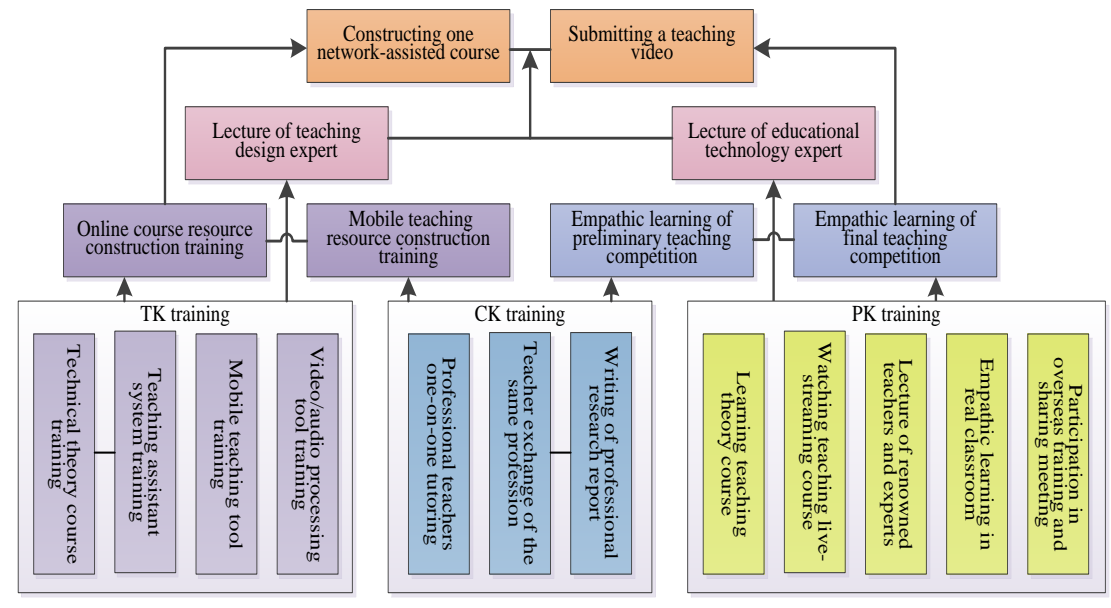

Fig. 2. Design drawing of ability improving strategy

Design of the first-layer (TK/CK/PK) improving strategy: TK training strategy is divided into four parts: technical theory course training, teaching assistance system training, mobile teaching tool training, and video/audio processing tool training. Technical theory course training aims to enable newly appointed teachers to systematically learn the application of various technical tools in education and teaching, and obtain an overall understanding of educational and teaching tools. The online learning form allows teachers to experience the convenience brought by online teaching. Teaching assistance system training integrates touch-type all-in-one machine, teaching software, and network learning platform. Newly appointed teachers are organized to participate in field training and actual operation, and understand various functions of touch-type all-in-one machine, teaching software, and network teaching platform so that they will be capable of doing basic operations. Mobile teaching tool training introduces all types of existing mobile teaching platforms to teachers. A platform is used as an example to organize a simulated mobile teaching 
activity, thereby enabling newly appointed teachers to experience the extensive functions of mobile teaching firsthand and enhance their interests in mobile teaching. For video/audio processing tool training, mainstream video/audio format, mainstream video/audio encoding format, mainstream video/audio recording software, mainstream video/audio editing software, and format conversion tools are introduced to newly appointed teachers [14]. Moreover, a practical case is combined for conducting practical operation training.

CK training strategy is divided into three parts: professional teachers' one-on-one tutoring, teacher exchange of the same profession, and writing of professional research report. Professional teachers' one-on-one tutoring means that the college where newly appointed teachers are assigned designate a tutor with good ethics, strong professional competence, and extensive teaching and scientific research experience to each newly appointed teacher. This practice provides specific guidance of professional knowledge in the form of master guiding apprentice. Teacher exchange of the same profession means regular or irregular exchange of teaching contents by taking subject group as the unit. Newly appointed teachers participate in each exchange activity and discuss their problems to improve their subject knowledge. Moreover, writing of professional research report can rely on real scientific research project application or simulated report writing. A scientific research team of one subject can be formed to conduct in-depth research on professional knowledge, repeatedly argue, and refine. Thus, high-quality professional declaration materials are formed, and newly appointed teachers are cultivated through scientific research that promotes professional knowledge improvement.

PK is a knowledge module, in which lack of knowledge is most serious among newly appointed teachers. Furthermore, training design is most critical with the most extensive training contents. The training strategy is divided into five parts: learning teaching theory course, watching teaching live-streaming course, lecture of renowned teachers and experts, empathic learning in real classroom, and participation in overseas training and sharing meeting. Learning of teaching theory course is implemented using online learning, online teaching theory course of a teaching master is introduced, and a 12-hour course learning is adopted. Thus, newly appointed teachers can understand and master systematic teaching theory, teaching strategy, and teaching method. In watching teaching-related live-streaming course, teaching-related live-stream contents of other domestic college teachers are pertinently selected and watched by newly appointed teachers to learn from them. Newly appointed teachers can watch in a place provided by the school together or independently select a viewing place, and the live-streaming system can effectively record the learning process. Lecture of renowned teachers and experts means recruiting prominent domestic teachers in the school to introduce their growth process and draw newly appointed teachers close to these teachers, thereby motivating their teaching enthusiasm and addressing their confusion through onsite interaction. In empathic learning in a real classroom, the subject group where newly appointed teachers are assigned is taken as a unit. They select courses established by two subject groups for empathic learning in a real classroom, do empathic learning records, and exchange with lecturer and students to improve their practical teaching abilities. Participation in 
overseas training and sharing meeting aims to improve international educational and teaching level of newly appointed teachers in our university and broaden their international horizon. Each semester, 20 teachers in our school complete a four-month teaching training task in a renowned university overseas, thereby enabling them to share their good training experience with newly appointed teachers.

Design of second-layer (TCK/PCK) training strategy: TCK training strategy is divided into two parts: online course resource construction training and mobile teaching resource construction training. Online course resources are the basic requirement for integrating educational technology and course contents in current period and the main construction content in the first-class course construction called "Double Ten Thousand Plan" of the Ministry of Education. In online course resource construction training, step-by-step training of practical case is adopted. This strategy vividly guides newly appointed teachers to use technical means to transform traditional teaching contents into online teaching resources and design multiple teaching content presentation modes according to characteristics of teaching contents, such as video, audio, animation, and 3D. Mobile learning is considered the future mainstream learning mode [15], in which the main priority is providing high-quality mobile teaching resources. As teachers in the new era, they should have the ability in mobile teaching resource construction. Thus, mobile teaching resource construction training is indispensable.

PCK training strategy is divided into two parts: empathic learning of preliminary teaching competition and empathic learning of final teaching competition, with the former implemented in each college. Participating teachers, who can use proper teaching methods to teach course contents, are representatives with the highest teaching level in each subject group. Thus, the empathic learning of preliminary teaching competition can guide newly appointed teachers to implement teaching combining their own professional courses and improve their course teaching knowledge. Final teaching competition is conducted based on preliminary competition. A teacher is recommended from each college after preliminary competition to participate in the final competition. Teachers participating in the final competition can represent the highest teaching level of their respective colleges. Empathic learning of final teaching competition can broaden teaching thoughts, teaching methods, and teaching organization forms of newly appointed teachers. Moreover, this type of learning can also provide notebooks, thereby enabling these teachers to participate in empathic learning activity with questions and improving the empathic learning effect.

Design of third-layer (TPK) training strategy: TPK training strategy is divided into two parts: lecture of teaching design expert and lecture of educational technology expert. Teaching design experts with the characteristics of the times are recruited to explain information-based teaching design based on flipped classroom, massive open online courses (MOOC), and small private online course (SPOC), as well as related matters needing attention, and to update information-based educational and teaching concepts of newly appointed teachers. Thus, they can have a clear, deep understanding of applying information technology to teaching design and implementation of classroom reform under the "Internet + " era, thereby improving 
their information-based teaching level. In the lecture of educational technology expert, emerging educational technological means are introduced, such as introducing the application of $5 \mathrm{G}$ Cloud and AR technology in the creation of brand-new immersion teaching [16] and introducing 5G remote holographic teaching application [17]. The educational technology horizon of newly appointed teachers is broadened, and the development direction of technology and education fusion is indicated.

Design of fourth-layer (TPACK) strategy: As the training assessment content, the improvement of the TPACK comprehensive ability is implemented through program-driven result presentation, namely, constructing one network-assisted course and submitting a teaching video. Each newly appointed teacher is required to construct a network course to facilitate full mastery of modern information technology, actively explore mixed teaching, become familiar with all kinds of classroom interaction tools, form "student-centered" new-type educational, teaching concept, and prepare for mixed teaching and network teaching. The constructed network courses embody information-based educational ability as one of the key assessment contents. The submitted teaching video is a real classroom teaching video or a simulated classroom teaching video recorded by each newly appointed teacher through a series of training and learning for one semester. This video is processed using video editing software and is suitable for online playing. The emphasis is on showing training result and video processing ability of newly appointed teachers. The submitted teaching video is also an assessment point and another embodiment of information-based teaching ability.

\subsection{Experimental design}

The quasi-experimental research method was adopted in this study to verify the effectiveness of this strategy (i.e., effectiveness of information-based educational and teaching training strategy for newly appointed college teachers based on the TPACK hierarchical model). A total of 65 newly appointed teachers in Guangdong University of Finance and Economics in 2018 and 118 in 2019 were selected as study objects. The 65 newly appointed teachers in 2018, who were mostly doctoral candidates who merely took jobs and did not accept the TPACK model-based training strategy, constituted the control group. The 118 newly appointed teachers in 2019 accepted the TPACK hierarchical model-based training strategy and constituted the experimental group. The concrete training contents were arranged according to the design model of the training strategy (see Table 1). A network-assisted course was constructed, a teaching video was taken and submitted as the evaluation objects in both groups, a set of evaluation index system was employed, and evaluation experts consisted of the same personnel. After a series of training and through expert evaluation, whether evaluation scores of newly appointed teachers could be elevated, and whether the training effect was evident were observed after the information-based educational and teaching training strategy based on the TPACK hierarchical model was adopted. 
Table 1. Training design based on the TPACK hierarchical model

\begin{tabular}{|c|c|}
\hline TPACK model & Concrete training contents for teachers newly appointed in 2019 \\
\hline \multirow{4}{*}{ TK } & $\begin{array}{l}\text { Online course learning of Application of Modern Educational Technology in University } \\
\text { Teaching }\end{array}$ \\
\hline & Basic special training of teaching assistance system \\
\hline & Special training of blackboard-based mobile teaching \\
\hline & Special training of mainstream video editing tool \\
\hline \multirow{3}{*}{ CK } & One-on-one teaching guidance of teacher representatives of the same profession \\
\hline & Salon of new and old teachers of the same profession \\
\hline & Completion of a professional scientific research report \\
\hline \multirow{5}{*}{$\mathrm{PK}$} & Online course learning of Improvement Training of Classroom Teaching Method \\
\hline & Participation in live-streaming learning at least twice \\
\hline & Expert lecture of college classroom teaching secrets in the information era \\
\hline & Participation in classroom empathic learning at least twice \\
\hline & Participation in result reporting meeting of overseas training personnel \\
\hline \multirow{2}{*}{ TCK } & Special training of blackboard resource construction and teaching application \\
\hline & Special training of mobile teaching resource production and utilization \\
\hline \multirow{2}{*}{ PCK } & Participation in empathic learning of preliminary teaching competition in the college \\
\hline & Participation in empathic learning of final teaching competition in the university \\
\hline \multirow{2}{*}{ TPK } & Special training class of mixed teaching design \\
\hline & Special lecture of 5G teaching application \\
\hline \multirow{2}{*}{ TPACK } & Construction of a network-assisted course based on Blackboard teaching platform \\
\hline & Submission of a teaching video not shorter than 15 min on Blackboard \\
\hline
\end{tabular}

\subsection{Evaluation form design and data analysis design}

1. Whether the evaluation form is suitable for factor analysis was tested using the Bartlett's sphericity model, which is presented in Equations (1) and (2):

$$
\begin{gathered}
K^{2}=\frac{1}{c}\left[(n-r) \ln M S E-\sum_{i=1}^{r}\left(n_{i}-1\right) \ln S_{i}^{2}\right] \\
c=1+\frac{1}{3(r-1)}\left[\sum_{i=1}^{r} \frac{1}{n_{i}-1}-\frac{1}{n-r}\right]
\end{gathered}
$$

where $\mathrm{r}$ denotes group, $S_{1}^{2}, S_{2}^{2}, \ldots, S_{r}^{2}$ express standard deviations, and MSE is the mean square error. Statistical magnitude K2 approximately follows an r-1 chisquare distribution.

2. The evaluation form was perfected through exploratory factor analysis (EFA) design. The EFA model was generalized into the factor model to express the relationships between observational variable xi and $\mathrm{m}$ public factors $\xi 1, \xi 2, \ldots, \xi \mathrm{m}$, using mathematical models (3), (4), (5), (6), and (7): 


$$
\begin{gathered}
x_{1}=\lambda_{11} \xi_{1}+\lambda_{12} \xi_{2}+\ldots+\lambda_{1 m} \xi_{m}+\delta_{1} \\
\ldots \ldots \\
x_{k}=\lambda_{k 1} \xi_{1}+\lambda_{k 2} \xi_{2}+\ldots+\lambda_{k m} \xi_{m}+\delta_{k} \\
m x=\Lambda_{x} \xi+\delta \\
x=\left(x_{1}, x_{2}, \ldots, x_{k}\right)^{T} \\
\xi=\left(\xi_{1}, \xi_{2}, \ldots, \xi_{m}\right) \\
\delta=\left(\delta_{1}, \delta_{2}, \ldots, \delta_{k}\right)^{T}
\end{gathered}
$$

where $x i$ is observational variable; $\xi i$ is public factor; $\delta \mathrm{i}$ is special factor of $x i$, also called error term and includes two parts, namely, uniqueness factor and error factor; $\lambda \mathrm{ij}$ is load of public factor; $\mathrm{m}$ is number of public factors $\xi 1, \xi 2, \ldots, \xi \mathrm{m}$, and $\mathrm{k}$ is number of observational variables $\mathrm{x} 1, \mathrm{x} 2, \ldots ., \mathrm{xk}$.

3. Evaluation values were analyzed in this study using mean value, standard deviation, standard deviation of mean value, comparative analysis method of $\mathrm{T}$ test, and high-layer proportional analysis method, where independent samples were used in the $\mathrm{t}$ test (no correlation exists between experimental treatment groups, namely, independent samples). This test was used to examine the differences of data acquired from two groups of uncorrelated subject samples. Independentsample $\mathrm{t}$ test statistics are shown in Equations (8), (9), and (10):

$$
\begin{gathered}
t=\frac{\overline{x_{1}}-\overline{x_{2}}}{\sqrt{\frac{\left(n_{1}-1\right) S_{1}^{2}+\left(n_{2}-1\right) S_{2}^{2}}{n_{1}-n_{2}-2}\left(\frac{1}{n_{1}}-\frac{1}{n_{2}}\right)}} \\
S_{1}^{2}=\frac{\sum_{i=1}^{n_{1}}\left(x_{i}-\overline{x_{1}}\right)^{2}}{n-1} \\
S_{2}^{2}=\frac{\sum_{i=1}^{n_{2}}\left(x_{i}-\overline{x_{2}}\right)^{2}}{n-1}
\end{gathered}
$$


where $\mathrm{n} 1$ and $\mathrm{n} 2$ are sample sizes; $\overline{x_{1}}$ and $\overline{x_{2}}$ are mean values of the samples in the two groups.

\section{$4 \quad$ Analysis and Discussion of Strategy Implementation Effect}

For all types of reasons, only 60 newly appointed teachers in Guangdong University of Finance and Economics in 2018 participated in network-assisted course construction and submitted 15-minute teaching videos in the end. By contrast, the figure in 2019 was 113. Therefore, numbers of newly appointed teachers in the control group and experimental group were 60 and 113, respectively. Whether evaluation scores of newly appointed teachers were elevated or whether such elevation was evident after accepting the information-based educational and teaching training strategy based on TPACK hierarchical model was determined through network-assisted course evaluation and teaching video evaluation.

Table 2 shows that 60 newly appointed teachers in 2018 accepted network-assisted course evaluation, where the average evaluation score is 77.3833 , standard deviation is 11.49958 , and standard error of mean value is 1.48459 . A total of 113 newly appointed teachers in 2019 accepted evaluation, where the average evaluation score is 80.7876 , standard deviation is 6.98142, and standard error of mean value is 0.65676 . The average score in 2019 improved by 3 points compared with that in 2018. Thus, the training effect is remarkable.

Table 2. Statistical scale of the network course evaluation

\begin{tabular}{|c|c|c|c|c|c|}
\hline Subject & Year & N & Mean value & $\begin{array}{c}\text { Standard } \\
\text { deviation }\end{array}$ & $\begin{array}{c}\text { Standard error } \\
\text { of mean value }\end{array}$ \\
\hline \multirow{2}{*}{ Network course evaluation } & 2018 & 60 & 77.3833 & 11.49958 & 1.48459 \\
\cline { 2 - 6 } & 2019 & 113 & 80.7876 & 6.98142 & 0.65676 \\
\hline
\end{tabular}

Table 3 shows the following findings: $F$ value is 2.643 and the significance probability Sig. is 0.106 , which is above the significance level 0.05 . Thus, the equal variance assumed cannot be rejected. The $\mathrm{T}$ test results in the first row under equal variance assumed are selected; the significance probability Sig. of double-side t test is 0.017 , which is below the significance level 0.05 ; and network course evaluation in 2019 is evidently improved. In addition, a certain interval span is observed from the $95 \%$ confidence interval of the mean value difference of samples, thereby indicating that network course evaluation within the two years is improved remarkably. Therefore, the information-based educational ability is considerably improved. 
Table 3. Independent-sample test of the network course evaluation

\begin{tabular}{|c|c|c|c|c|c|c|c|c|c|c|}
\hline \multirow{3}{*}{ Subject } & \multirow{3}{*}{ Assumed } & \multirow{2}{*}{\multicolumn{2}{|c|}{$\begin{array}{l}\text { Levene's Test for } \\
\text { Quality of } \\
\text { Variances }\end{array}$}} & \multicolumn{7}{|c|}{ T-test for Equality of Means } \\
\hline & & & & \multirow[t]{2}{*}{$t$} & \multirow[t]{2}{*}{$d f$} & \multirow{2}{*}{$\begin{array}{c}\text { Sig. } \\
\text { (2-tailed) }\end{array}$} & \multirow{2}{*}{$\begin{array}{c}\text { Mean } \\
\text { Difference }\end{array}$} & \multirow{2}{*}{$\begin{array}{l}\text { Std. Error } \\
\text { Difference }\end{array}$} & \multicolumn{2}{|c|}{$\begin{array}{l}\text { 95\% Confidence } \\
\text { Interval of the } \\
\text { Differential }\end{array}$} \\
\hline & & $\boldsymbol{F}$ & Sig. & & & & & & Lower & Upper \\
\hline \multirow{2}{*}{$\begin{array}{l}\text { Network } \\
\text { course } \\
\text { evaluation }\end{array}$} & \begin{tabular}{|l} 
Equal \\
variance \\
assumed
\end{tabular} & 2.643 & 0.106 & -2.420 & 171 & 0.017 & -3.40428 & 1.40669 & -6.18100 & -0.62756 \\
\hline & \begin{tabular}{|l} 
Equal \\
variance \\
not \\
assumed
\end{tabular} & & & -2.097 & 82.684 & 0.039 & -3.40428 & 1.62337 & -6.63328 & -0.17527 \\
\hline
\end{tabular}

Fig. 3 shows that the proportion occupied by high layers in the aspect of network course evaluation scores in 2019 is evidently larger than that in 2018, whereas the proportion occupied by low layers in 2019 is small. Thus, the effect is evident.

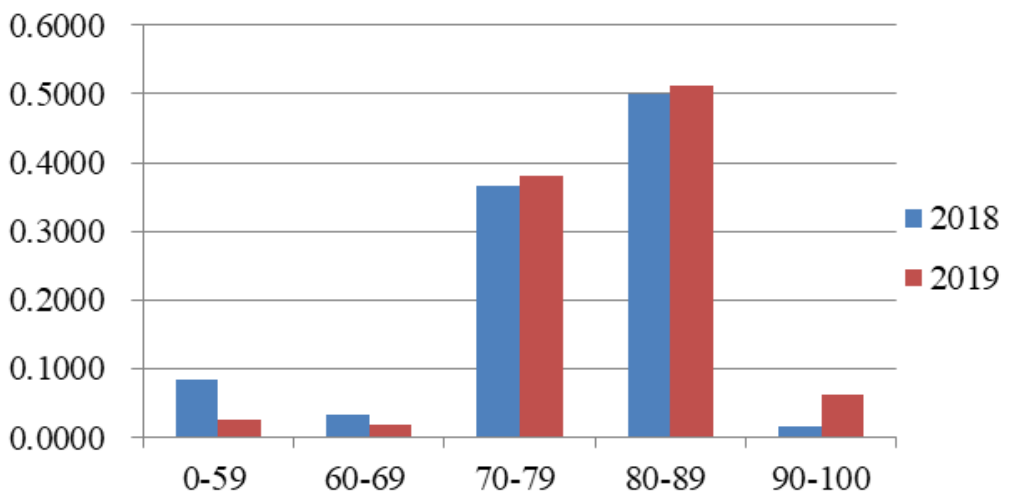

Fig. 3. Scale drawing of the score segments in the network course evaluation

Table 4 shows that 60 newly appointed teachers in 2018 accepted teaching video evaluation, in which the average evaluation score is 75.4333, standard deviation is 14.84195 , and standard error of mean value is 1.91609. A total of 113 newly appointed teachers in 2019 accepted evaluation, where the average evaluation score is 83.8584, standard deviation is 4.19368, and standard error of mean value is 0.39451 . The average score in 2019 is higher than that in 2018 by approximately 8 points. Thus, the training effect is evident. 
Table 4. Statistical scale of the teaching video evaluation

\begin{tabular}{|c|c|c|c|c|c|}
\hline \multicolumn{1}{|c|}{ Subject } & Year & $\mathbf{N}$ & Mean Value & $\begin{array}{c}\text { Standard } \\
\text { Deviation }\end{array}$ & $\begin{array}{c}\text { Standard Error } \\
\text { of Mean Value }\end{array}$ \\
\hline $\begin{array}{l}\text { Teaching video } \\
\text { evaluation }\end{array}$ & 2018 & 60 & 75.4333 & 14.84195 & 1.91609 \\
\cline { 2 - 6 } & 2019 & 113 & 83.8584 & 4.19368 & 0.39451 \\
\hline
\end{tabular}

Table 5 shows the following findings: $\mathrm{F}$ value is 31.335 ; significance probability Sig. is 0 , which is below the significance level 0.05 , thereby rejecting the equal variance assumed. The $t$ test results in the second row under equal variance assumed are selected. The significance probability Sig. of the double-side t test is 0 , which is below the significance level 0.05. Thus, the teaching video evaluation in 2019 is evidently improved. In addition, a certain interval span is observed from $95 \%$ confidence interval of mean value difference of samples. This result also indicates that the teaching video evaluation within two years and information-based teaching ability are remarkably improved.

Table 5. Independent-sample test of teaching video evaluation

\begin{tabular}{|c|c|c|c|c|c|c|c|c|c|c|}
\hline \multirow{3}{*}{ Subject } & \multirow{3}{*}{ Assumed } & \multirow{2}{*}{\multicolumn{2}{|c|}{$\begin{array}{c}\text { Levene's Test } \\
\text { for Quality of } \\
\text { Variances }\end{array}$}} & \multicolumn{7}{|c|}{ T-test for Equality of Means } \\
\hline & & & & \multirow[t]{2}{*}{$t$} & \multirow[t]{2}{*}{$d f$} & \multirow[t]{2}{*}{$\begin{array}{c}\text { Sig. } \\
\text { (2-tailed) }\end{array}$} & \multirow[t]{2}{*}{$\begin{array}{c}\text { Mean } \\
\text { Difference }\end{array}$} & \multirow[t]{2}{*}{$\begin{array}{l}\text { Std. Error } \\
\text { Difference }\end{array}$} & \multicolumn{2}{|c|}{$\begin{array}{l}\text { 95\% Confidence } \\
\text { Interval of the } \\
\text { Differential }\end{array}$} \\
\hline & & $\boldsymbol{F}$ & Sig. & & & & & & Lower & Upper \\
\hline \multirow{2}{*}{$\begin{array}{l}\text { Teaching } \\
\text { Video } \\
\text { Evaluatio } \\
\mathrm{n}\end{array}$} & $\begin{array}{l}\text { Equal } \\
\text { Variance } \\
\text { Assumed }\end{array}$ & 31.335 & 0 & -5.638 & 171 & 0 & -8.42507 & 1.49441 & -11.37494 & -5.47521 \\
\hline & $\begin{array}{l}\text { Unequal } \\
\text { Variance } \\
\text { Assumed }\end{array}$ & & & -4.307 & 64.048 & 0 & -8.42507 & 1.95628 & -12.33314 & -4.51701 \\
\hline
\end{tabular}

Fig. 4 shows that the proportion occupied by high layers (over 80 scores) in 2019 teaching video evaluation is generally above $80 \%$, and substantially higher than that in 2018. However, the proportion occupied by the low layers in 2019 is zero. Thus, the training effect is extremely evident. 


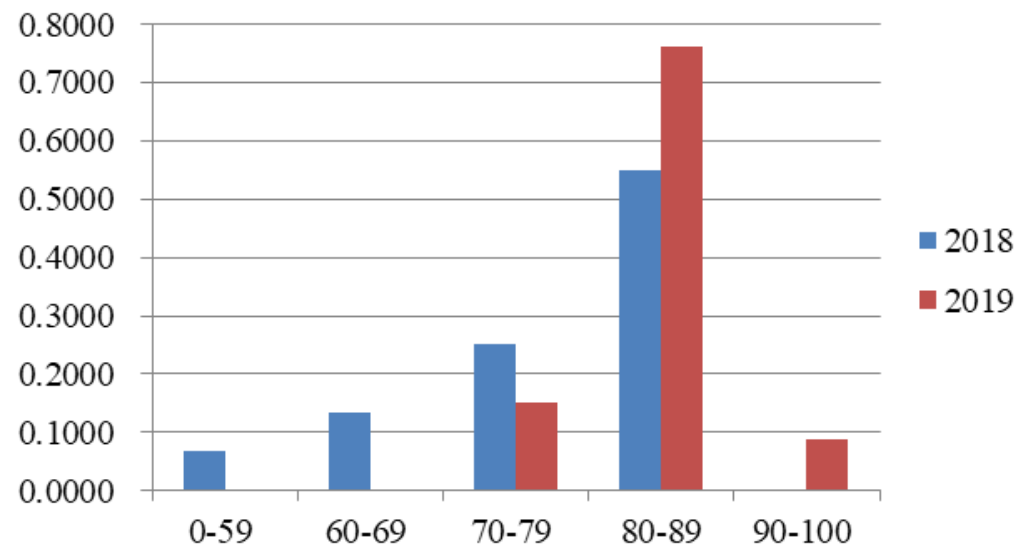

Fig. 4. Scale drawing of the score segments in the teaching video evaluation

\section{Conclusion}

Newly appointed college teachers are the future of education, and their information-based educational and teaching abilities influence college development to a great extent. Thus, improving their information-based educational and teaching abilities is the key to pre-job training. Information-based educational and teaching abilities of newly appointed college teachers were designed in this study based on the TPACK hierarchical model. This training strategy was applied to 2019 informationbased educational and teaching training in Guangdong University of Finance and Economics. The evaluation result was compared through a statistical analysis with that at the end of 2018, when this training strategy was not implemented. The following conclusions are drawn.

(1) This research was conducted based on three core factors and four composite factors of TPACK. A four-layer model (i.e., first, second, third, and fourth layers are TK/PK/CK, TCK/PCK, TPK, and TPACK, respectively) was designed following the idea of hierarchy, which was reasonable and effective.

(2) According to the characteristics of newly appointed teachers, namely, rich professional knowledge, owning technical knowledge, and lacking teaching knowledge; and the four-layer idea, the improvement strategy of 20 training programs corresponding to seven factors was designed, which could effectively elevate network course evaluation scores and teaching video evaluation scores by a large margin.

(3) The T test results indicated that the information-based educational and teaching ability improving strategy based on TPACK hierarchical model is of remarkable effect and can improve educational technology level and teaching level of newly appointed teachers (i.e., information-based educational level). 
Lastly, constructing a substantially reasonable evaluation system for this information-based educational and teaching training strategy based on TPACK hierarchical model will be the subsequent research direction.

\section{Acknowledgement}

This work was supported by the Education Project of Industry-University Cooperation (201801186008), the Guangdong Provincial Science and Technology Program (2017A040405051), the Higher Education Teaching Reform Project of Guangdong in 2017, Foundation for Distinguished Young Talents in Higher Education of Guangdong (2017WQNCX055), National educational information technology research project (176140006).

\section{$7 \quad$ References}

[1] Doering, A., Veletsianos, G., Scharber, C. and Miller, C. Using the technological, pedagogical, and content knowledge framework to design online learning environments and professional development. Journal of Educational Computing Research, 2009, vol. 41(3), pp. 319-346. https://doi.org/10.2190/ec.41.3.d

[2] Graham, C. R., Borup, J. and Smith, N. B. Using TPACK as a framework to understand teacher candidates' technology integration decisions. Journal of Computer Assisted Learning, 2012, vol. 28(6), pp. 530-546. https://doi.org/10.1111/j.1365-2729.2011.00472.x

[3] Hagerman, M.S., Keller, A. and Spicer, J.L. The MSU educational technology certificate courses and their impact on teachers' growth as technology integrators. TechTrends, 2013, vol. 57(3), pp. 26-33. https://doi.org/10.1007/s11528-013-0659-8

[4] Elas, N. I. B., Abd Majid, F. B. and Suthagar, A. Development of technological pedagogical content knowledge (TPACK) for english teachers: The validity and reliability. International Journal of Emerging Technologies in Learning, 2019, vol. 14(20), pp. 18-33. https://doi.org/10.3991/ijet.v14i20.11456

[5] Xu Xuemin. Based on TPCK model, the research on the cultivation of the informationbased teaching ability of young teachers in colleges and universities. Journal of Nanjing Institute of Industrial Technology, 2018, vol. 18(2), pp. 77-80.

[6] Liu Lei and Dai Xinlai. Research on the cultivation of pre-service teachers' informational teaching ability from the perspective of TPACK theory. Software Guide, 2019, vol. 18(12), pp. 267-270.

[7] Pifarré, M. and Martí, L. A technology-enhanced pedagogical framework to promote collaborative creativity in secondary education. In Digital Technologies: Sustainable Innovations for Improving Teaching and Learning. Springer, Cham, 2018. https://doi.org/ 10.1007/978-3-319-73417-0_14

[8] Hu Lun and Xie Weidong. A study on the revision of college teachers' TPACK ability scale. Software Guide, 2018, vol. 17(11), pp. 1-3.

[9] Valtonen, T., Sointu, E., Kukkonen, J., Mäkitalo, K., Hoang, N., Häkkinen, P., Järvelä, S., Näykki, P., Virtanen, A., Pöntinen, S. and Kostiainen, E. Examining pre-service teachers' technological pedagogical content knowledge as evolving knowledge domains: A longitudinal approach. Journal of Computer Assisted Learning, 2019, vol. 35(4), pp. 491502. https://doi.org/10.1111/jcal.12353 
[10] Akyuz, D. Measuring technological pedagogical content knowledge (TPACK) through performance assessment. Computers \& Education, 2018, vol. 125(1), pp. 212-225. https:// doi.org/10.1016/j.compedu.2018.06.012

[11] Hewitt, J. Reviewing the handbook of technological pedagogical content knowledge (TPCK) for educators. Canadian Journal of Science, Mathematics and Technology Education, 2008, vol. 8(4), pp. 355-360. https://doi.org/10.1080/14926150802506274

[12] Koehler, M. J., Mishra, P., Kereluik, K., Shin, T. S. and Graham, C. R. The technological pedagogical content knowledge framework. Handbook of Research on Educational Communications and Technology, New York, NY: Springer, 2014. https://doi.org/10.10 07/978-1-4614-3185-5 9

[13] Koh, J. H. L., Chai, C. S., Benjamin, W. and Hong, H. Y. Technological pedagogical content knowledge (TPACK) and design thinking: A framework to support ICT lesson design for 21st century learning. The Asia-Pacific Education Researcher, 2015, vol. 24(3), pp. 535-543. https://doi.org/10.1007/s40299-015-0237-2

[14] Al Hashimi, S. A., Al Muwali, A. A., Zaki, Y. E. and Mahdi, N. A. The effectiveness of social media and multimedia-based pedagogy in enhancing creativity among art, design, and digital media students. International Journal of Emerging Technologies in Learning, 2019, vol. 14(21), pp. 176-190. https://doi.org/10.3991/ijet.v14i21.10596

[15] Al-Balushi, S.M. and Al-Abdali, N.S. Using a moodle-based professional development program to train science teachers to teach for creativity and its effectiveness on their teaching practices. Journal of Science Education and Technology, 2015, vol. 24(4), pp. 461-475. https://doi.org/10.1007/s10956-014-9530-8

[16] Lin, Z., Gao, Z., Huang, L., Chen, C. Y. and Chao, H. C. Hybrid architecture performance analysis for device-to-device communication in $5 \mathrm{~g}$ cellular network. Mobile Networks and Applications, 2015, vol. 20(6), pp. 713-724. https://doi.org/10.1007/s11036-015-0566-7

[17] Egorov, N. V., Trofimov, V. V., Antonov, S. R., Fedorov, A. G. and Antonova, L. I. (2014). Studying the electrophysical parameters of a holographic microscope. Journal of Surface Investigation: X-ray, Synchrotron and Neutron Techniques, 2014, vol. 8(4), pp. 745-747. https://doi.org/10.1134/s1027451014040259

\section{Authors}

Hanhui Lin is a PHD candidate in School of Information Technology in Education, South China Normal University, Guangzhou 510631, China. He is a senior engineer in the Center of Faculty Development and Educational Technology, Guangdong University of Finance and Economics, Guangzhou 510320, China.

Muxiong Huang (corresponding author) is a professor in School of Information Technology in Education, South China Normal University, Guangzhou 510631, China. He is also a professor in Guangdong University of Education, Guangzhou 510303, China.

Article submitted 2020-04-29. Resubmitted 2020-06-03. Final acceptance 2020-06-05. Final version published as submitted by the authors. 